\title{
Management of necrotizing pneumonia and pulmonary gangrene: A case series and review of the literature
}

\author{
Neela Chatha MD FRCPC ${ }^{1}$, Dalilah Fortin MD FRCSC $2,3,4$, Karen J Bosma MD FRCPC ${ }^{1,3,5}$
}

N Chatha, D Fortin, KJ Bosma. Management of necrotizing pneumonia and pulmonary gangrene: $\mathrm{A}$ case series and review of the literature. Can Respir J 2014;21(4):239-245.

BACKGROUND: Necrotizing pneumonia is an uncommon but severe complication of bacterial pneumonia, associated with high morbidity and mortality. The availability of current data regarding the management of necrotizing pneumonia is limited to case reports and small retrospective observational cohort studies. Consequently, appropriate management for these patients remains unclear.

OBJECTIVE: To describe five cases and review the available literature to help guide management of necrotizing pneumonia.

METHODS: Cases involving five adults with respiratory failure due to necrotizing pneumonia admitted to a tertiary care centre and infected with Streptococcus pneumoniae $(\mathrm{n}=3)$, Klebsiella pneumoniae $(\mathrm{n}=1)$ and methicillinresistant Staphylococcus aureus $(\mathrm{n}=1)$ were reviewed. All available literature was reviewed and encompassed case reports and retrospective reviews dating from 1975 to the present.

RESULTS: All five patients received aggressive medical management and consultation by thoracic surgery. Three patients underwent surgical procedures to debride necrotic lung parenchyma. Two of the five patients died in hospital.

CONCLUSIONS: Necrotizing pneumonia often leads to pulmonary gangrene. Computed tomography of the thorax with contrast is recommended to evaluate the pulmonary vascular supply. Further study is necessary to determine whether surgical intervention, in the absence of pulmonary gangrene, results in better outcomes.

Key Words: Lung abscess; Lung resection; Necrotizing pneumonia; Pneumonia; Pulmonary gangrene

Tecrotizing pneumonia is a rare and severe complication of bacter1 ial community-acquired pneumonia (CAP). Lying on a spectrum between lung abscess and pulmonary gangrene $(1,2)$, necrotizing pneumonia is characterized by pulmonary inflammation with consolidation, peripheral necrosis and multiple small cavities (3). Compromise of the bronchial and pulmonary vascular supply $(4,5)$ has the potential for devitalization of lung parenchyma. The lack of blood supply to the underperfused areas impedes delivery of antibiotics, allowing for uncontrolled infection and further destruction of lung tissue. Pulmonary gangrene is the "final stage in a continuum of progressive devitalization of pulmonary parenchyma" (5) and is characterized by "sloughing of a pulmonary segment or lobe" (5).

Managing patients with necrotizing pneumonia is challenging because there are no firm guidelines outlining when to proceed from medical to surgical management. A small number of case reports and retrospective studies examining the treatment of necrotizing pneumonia and pulmonary gangrene are available (1-4,6-9). The mainstay of treatment is supportive with appropriate antibiotics; however, if patients fail to improve, surgery may be a life-saving option.

We reviewed five patients with necrotizing pneumonia and/or pulmonary gangrene admitted to the intensive care unit (ICU) of London Health Sciences Centre (LHSC, London, Ontario), a tertiary care centre, over a six-year period. The present review adds to the collective experience dealing with this disease.

\section{La prise en charge de la pneumonie nécrosante et de la gangrène pulmonaire : une série de cas et une analyse bibliographique}

HISTORIQUE : La pneumonie nécrosante est une complication peu courante, mais grave, de la pneumonie bactérienne, qui s'associe à une morbidité et une mortalité élevées. Les données sur sa prise en charge sont limitées à des rapports de cas et à de petites études rétrospectives de cohortes par observation. Par conséquent, la prise en charge convenable de ces patients n'est pas claire.

OBJECTIF : Décrire cinq cas et analyser les publications pour orienter la prise en charge de la pneumonie nécrosante.

MÉTHODOLOGIE : Les chercheurs ont analysé le cas de cinq adultes ayant une insuffisance respiratoire causée par la pneumonie nécrosante, hospitalisés dans un centre de soins tertiaires et infectés par le Streptococcus pneumoniae $(n=3)$, le Klebsiella pneumoniae $(n=1)$ ou le Staphylococcus aureus résistant à la méthicilline $(n=1)$. Ils ont analysé toutes les publications et inclus les rapports de cas et les analyses rétrospectives de 1975 à maintenant.

RÉSULTATS : Les cinq patients ont reçu une prise en charge médicale dynamique et une consultation en chirurgie thoracique. Trois patients ont subi des interventions chirurgicales pour débrider un parenchyme pulmonaire nécrotique. Deux des cinq patients sont décédés à l'hôpital. CONCLUSION : La pneumonie nécrosante est souvent responsable d'une gangrène pulmonaire. La tomodensitométrie de contraste du thorax est recommandée pour évaluer la capacité vasculaire pulmonaire. D'autres études s'imposent pour déterminer si, en l'absence de gangrène pulmonaire, une intervention chirurgicale donne de meilleurs résultats cliniques.

\section{Case 1}

\section{CASE PRESENTATIONS}

A 56-year-old male truck driver presented to a community hospital in the United States with cough, fever and dyspnea (Table 1). Chest $\mathrm{x}$-ray (CXR) revealed right lung consolidation with effusion. A chest tube was placed for presumed empyema. The patient was intubated, and bronchoscopy revealed methicillin-resistant Staphylococcus aureus (MRSA) in bronchoalveolar lavage (BAL) cultures. Blood cultures grew methicillin-sensitive $S$ aureus.

After 10 days in a community ICU, the patient was transferred to LHSC for ongoing management. On his second day at LHSC, he was taken to the operating room, given new computed tomography (CT) scan findings suggesting right-sided empyema and necrosing pulmonary tissue (Table 2). Bilobectomy and right-sided decortication were performed. Pathology confirmed diffuse necrotizing lobar pneumonia.

Despite aggressive treatment postoperatively, he failed to improve and one month after his admission to hospital, life support was withdrawn.

\section{Case 2}

A 32-year-old male sheep farmer presented to a community hospital after feeling unwell for one week. CXR revealed right lower lobe (RLL) pneumonia with effusion. He was intubated for hypoxic respiratory failure and a chest tube was inserted for a presumed empyema. CT

${ }^{1}$ Department of Medicine; ${ }^{2}$ Department of Surgery; Divisions of ${ }^{3}$ Critical Care and ${ }^{4}$ Thoracic Surgery; ${ }^{5}$ Division of Respirology, London Health Sciences Centre, London, Ontario

Correspondence: Dr Karen J Bosma, London Health Sciences Centre-University Hospital, 339 Windermere Road, Room B2-194, London,

Ontario N6A 5A5. Telephone 519-663-3531, fax 519-663-8813, e-mail karenj.bosma@lhsc.on.ca 
TABLE 1

Baseline characteristics, sepsis severity and pathogen isolated for the study population

\begin{tabular}{|c|c|c|c|c|c|c|c|c|c|}
\hline \multirow[b]{2}{*}{ Case } & \multirow[b]{2}{*}{$\begin{array}{l}\text { Age, } \\
\text { years }\end{array}$} & \multirow[b]{2}{*}{ Sex } & \multirow[b]{2}{*}{ MHx } & \multirow[b]{2}{*}{ Presenting signs/Sx } & \multicolumn{4}{|c|}{ Sepsis* } & \multirow[b]{2}{*}{ Pathogen } \\
\hline & & & & & $\begin{array}{l}\text { Heart rate, } \\
\text { beats } / \mathrm{min}\end{array}$ & Temperature, ${ }^{\circ} \mathrm{C}$ & $\begin{array}{c}\text { White blood cell } \\
\text { count, } \times 10^{9} / \mathrm{L}\end{array}$ & $\begin{array}{c}\text { Respiratory rate, } \\
\text { breaths } / \mathrm{min}\end{array}$ & \\
\hline 1 & 56 & Male & $\begin{array}{l}\text { COPD } \\
\text { Hypertension } \\
\text { Chronic kidney disease } \\
\text { Current smoker }\end{array}$ & $\begin{array}{l}\text { Cough } \\
\text { Fever } \\
\downarrow \text { Blood pressure } \\
\text { Hypoxia }\end{array}$ & 141 & 38.9 & 5.7 & 28 & $\begin{array}{l}\text { Methicillin- } \\
\text { resistant } \\
\text { Staphyolcoccus } \\
\text { aureus }\end{array}$ \\
\hline 2 & 32 & Male & $\begin{array}{l}\text { Nil } \\
\text { Nonsmoker }\end{array}$ & $\begin{array}{l}\text { Cough } \\
\text { Fever } \\
\text { Hypoxia }\end{array}$ & 150 & 39.2 & 5.1 & 30 & $\begin{array}{r}\text { Streptococcus } \\
\text { pneumoniae }\end{array}$ \\
\hline 3 & 50 & Female & $\begin{array}{l}\text { DMII } \\
\text { Hypothyroidism } \\
\text { Nonsmoker }\end{array}$ & $\begin{array}{l}\text { Cough } \\
\text { Fever } \\
\text { Hypoxia }\end{array}$ & 95 & 38.7 & 2.9 & 28 & $\begin{array}{l}\text { Klebsiella } \\
\text { pneumoniae }\end{array}$ \\
\hline 4 & 46 & Male & $\begin{array}{l}\text { Hypertension } \\
\text { Hypercholesterolemia } \\
\text { Alcohol abuse } \\
\text { Current smoker }\end{array}$ & Hypoxia & 116 & 38.2 & 1.4 & 35 & S pneumoniae \\
\hline
\end{tabular}

*Sepsis was defined by meeting the systemic inflammatory response syndrome (SIRS) with an active infection. SIRS can be defined as two or more of the following criteria: fever $<36.0^{\circ} \mathrm{C}$ or $>38.3^{\circ} \mathrm{C}$, heart rate $>90$ beats $/ \mathrm{min}$, respiratory rate $>30$ breaths $/ \mathrm{min}$, white blood cell count $>12 \times 10^{9} / \mathrm{L}$ and/or $<4 \times 10^{9} / \mathrm{L}$ and/or $>10 \%$ immature cells (Society of Critical Care Medicine/European Society of Intensive Care Medicine/American College of Chest Physicians/American Thoracic Society/Surgical Infection Society 2003 sepsis definitions). $\downarrow$ Decreased; COPD Chronic obstructive pulmonary disease; DMII Type 2 diabetes mellitus; MHx Medical history; Sx Symptoms

TABLE 2

Severity of illness, interventions and outcomes of the study population

\begin{tabular}{|c|c|c|c|c|c|c|c|c|}
\hline & APACHE III score & SOFA score or & & & SOFA score on & Pathology & & \\
\hline Case & on admission & admission & Interventions & Surgery & OR day & findings & MV, days & Outcome \\
\hline \multirow[t]{4}{*}{1} & \multirow[t]{4}{*}{80} & \multirow[t]{4}{*}{5} & Intubation & \multirow{4}{*}{$\begin{array}{l}\text { Yes: thoracotomy, } \\
\text { bilobectomy, } \\
\text { decortication }\end{array}$} & \multirow[t]{4}{*}{9} & \multirow{4}{*}{$\begin{array}{l}\text { Diffuse necrotizing } \\
\text { pneumonia }\end{array}$} & \multirow[t]{4}{*}{29} & \multirow[t]{4}{*}{ Deceased } \\
\hline & & & Bronchoscopy & & & & & \\
\hline & & & Chest tubes & & & & & \\
\hline & & & Thoracic surgery consult & & & & & \\
\hline \multirow[t]{4}{*}{2} & \multirow[t]{4}{*}{117} & \multirow[t]{4}{*}{7} & Intubation & \multirow{4}{*}{$\begin{array}{l}\text { Yes: thoracotomy, } \\
\text { wedge resection, } \\
\text { decortication }\end{array}$} & \multirow[t]{4}{*}{7} & \multirow{7}{*}{$\begin{array}{l}\text { Hemorrhagic } \\
\text { necrosis + } \\
\text { abscess and } \\
\text { organizing } \\
\text { pneumonia }\end{array}$} & \multirow[t]{4}{*}{23} & \multirow[t]{4}{*}{ D/C home } \\
\hline & & & CT thorax (+ contrast) & & & & & \\
\hline & & & Chest tubes & & & & & \\
\hline & & & Thoracic surgery consult & & & & & \\
\hline \multirow[t]{3}{*}{3} & \multirow[t]{3}{*}{119} & \multirow[t]{3}{*}{12} & Intubation & \multirow[t]{3}{*}{ No } & \multirow[t]{3}{*}{$\mathrm{n} / \mathrm{a}$} & & \multirow[t]{3}{*}{17} & \multirow[t]{3}{*}{ Deceased } \\
\hline & & & Bronchoscopy & & & & & \\
\hline & & & CT thorax & & & & & \\
\hline \multirow{4}{*}{4} & \multirow{4}{*}{146} & \multirow{4}{*}{13} & Bronchoscopy & \multirow{4}{*}{$\begin{array}{l}\text { Yes: thoracotomy, } \\
\text { debridement }\end{array}$} & \multirow{4}{*}{10} & \multirow{4}{*}{$\begin{array}{l}\text { Necrotic lung } \\
\text { tissue with } \\
\text { extensive } \\
\text { pneumonia and } \\
\text { abscess }\end{array}$} & \multirow{4}{*}{36} & \multirow{4}{*}{ D/C home } \\
\hline & & & CT thorax (+ contrast) & & & & & \\
\hline & & & Chest tubes & & & & & \\
\hline & & & Thoracic surgery consult & & & & & \\
\hline 5 & Not able to & 9 & Intubation & No & $\mathrm{n} / \mathrm{a}$ & & 21 & $\mathrm{D} / \mathrm{C}$ home \\
\hline & calculate & & Bronchoscopy & & & & & \\
\hline & & & $\mathrm{CT}$ thorax (+ contrast) & & & & & \\
\hline & & & Chest tube & & & & & \\
\hline & & & Thoracic surgery consult & & & & & \\
\hline
\end{tabular}

In the critically ill, the degree of multiorgan dysfunction plays a large role in morbidity and mortality. Given this, Sepsis-related Organ Assessment (SOFA) scores were calculated for each patient retrospectively to evaluate their status on the day of surgery compared with day of admission. The SOFA score evaluates the respiratory (partial pressure of oxygen/fraction of inhaled oxygen ratio), hematological (platelets), hepatic (bilirubin), cardiovascular (blood pressure and inotropes), renal (creatinine) and central nervous systems (Glasgow Coma Scale) with higher scores indicating worse degrees of organ failure. APACHE Acute Physiology and Chronic Health Evaluation; CT Computed tomography; D/C Discharge; MV Mechanical ventilation; n/a Not applicable; OR Operating room 

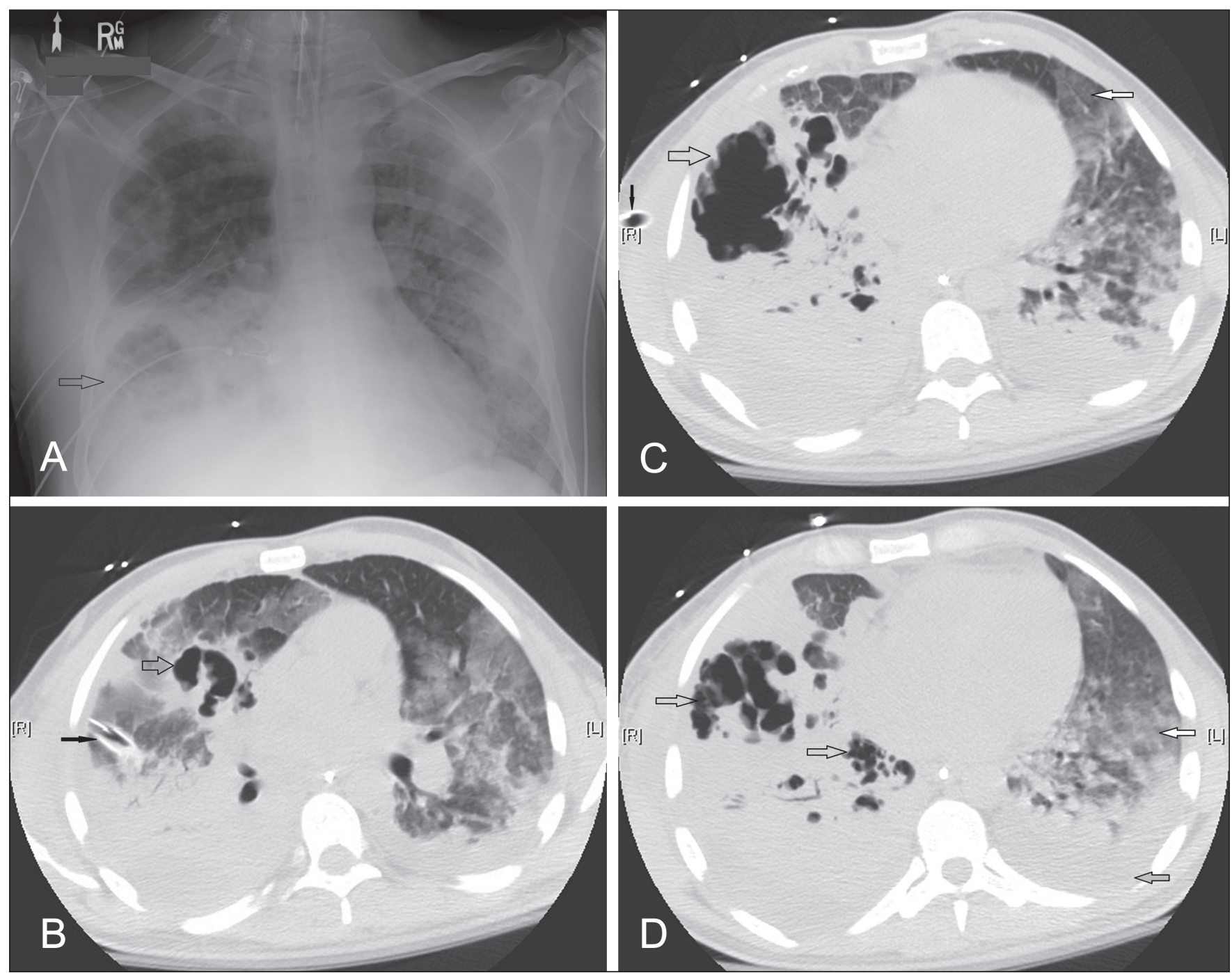

Figure 1) A Chest x-ray for case 2. Multifocal pneumonia with an area of lucency in the right lower lobe (open arrow), concerning for abscess formation. B, $\mathrm{C}$ and $\mathrm{D}$ Noncontrast computed tomography scan of the thorax, axial views for case 2, performed within 24 h of chest $x$-ray (A) showing large irregular cavities destroying the right middle and right lower lobes (open arrows), the extent of which was not apparent on plain film. A chest tube is present on the right side (solid black arrow). In addition there are widespread multifocal ground-glass opacities (solid white arrow) in the left lung with a moderate left pleural effusion (solid grey arrow)

scan with contrast revealed consolidation of the entire left lower lobe and the RLL. Pulmonary vasculature was patent. Following intubation, he was transferred to LHSC for further management. Cultures from blood and BAL were positive for pansensitive Streptococcus pneumoniae (mucous strain).

Serial CT scans of the thorax demonstrated very rapid progression of the right-sided consolidation, with large cavities suggestive of pulmonary abscess and necrotizing pneumonia involving the RLL and right middle lobe (RML) (Figure 1). Nine days after presentation, the patient underwent a thoracotomy for unroofing of an abscess and debridement of the RLL, a wedge resection of the RML to remove necrotic lung, and decortication along the RML and RLL. Pathology revealed hemorrhagic necrosis with acute inflammation and fibrinous and organizing pneumonia.

The patient had a prolonged stay in the ICU, requiring tracheostomy, but was successfully weaned off ventilation and discharged home.

\section{Case 3}

A 50-year-old woman presented to her community hospital with sepsis. CXR revealed right-sided pneumonia. She was started empirically on azithromycin and penicillin. Two days later, she had increased dyspnea and was intubated for hypoxic respiratory failure. Vasopressor support was initiated at the time of her transfer to LHSC. She underwent two bronchoscopies and two chest tubes were inserted for suspected empyema. BAL, tracheal aspirate and pleural fluid all grew Klebsiella pneumoniae, which was fully antibiotic sensitive. CT of the thorax revealed consolidation of the right lung, with only a small portion of the upper lobe spared. Multiple cavities (largest $6.0 \mathrm{~cm}$ in diameter) were present, along with extensive necrosis.

Thoracic surgery was consulted 18 days after initial presentation but she was deemed too unstable for surgical intervention at that time. She was placed on extracorporeal membrane oxygenation following the development of a large bronchopleural fistula. After 17 days in the ICU with no improvement, a decision to withdraw life support was made.

\section{Case 4}

A 46-year-old man presented to a community hospital with shortness of breath and cough. On examination, he was hypotensive and hypoxemic, and endotracheal intubation was performed. CT of the thorax with contrast revealed extensive RLL consolidation, with patency of the central pulmonary vasculature. BAL grew pansensitive $S$ pneumoniae. He remained in the community hospital ICU for 10 days until he was transferred to LHSC because of failure to improve. Repeat CT 

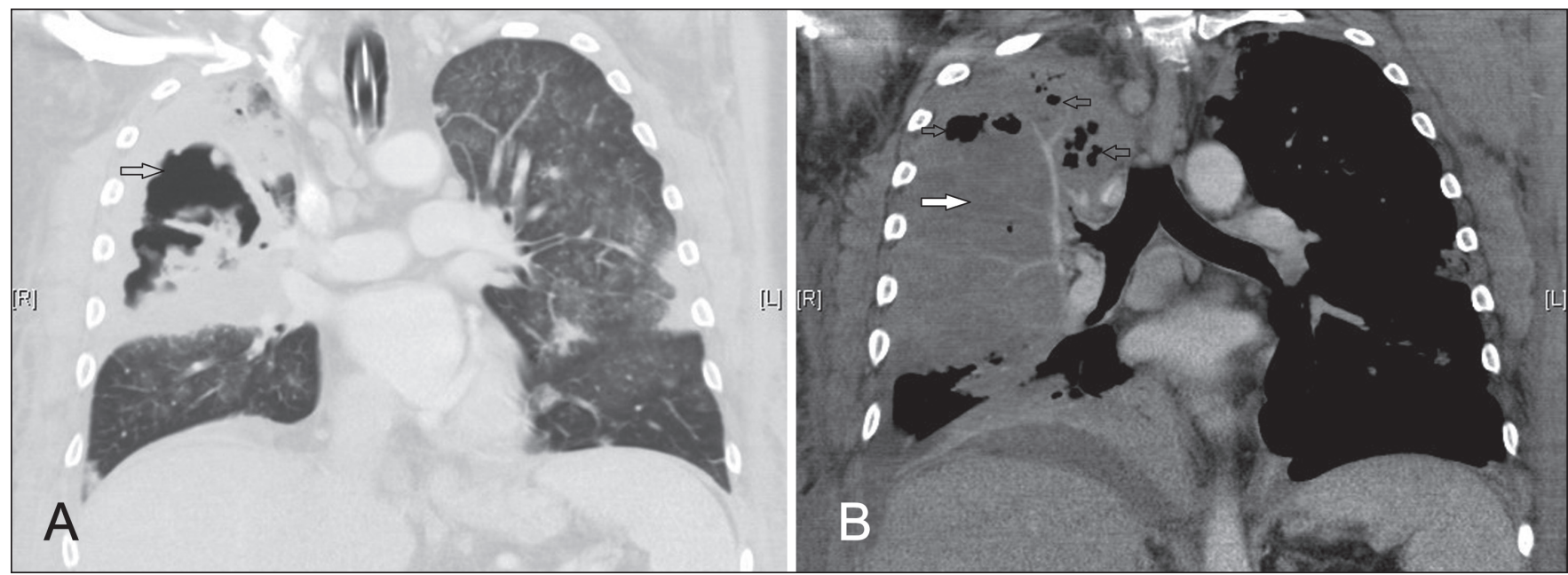

Figure 2) Computed tomography scan of the thorax with contrast, coronal views, for case 4. A There is a large cavity in the right upper lobe (open arrow) and B multiple smaller abscesses located posteriorly in the right apex (open arrows), with decreased attenuation of the right upper lobe (solid white arrow), although the vessels in the right upper lobe are patent. The decreased perfusion and multiple small abscesses in addition to the large abscess cavity are consistent with a radiographic diagnosis of necrotizing pneumonia

of the thorax subsequently revealed extensive right-sided pneumonia with cavitation and necrosis, requiring monitoring for potential pulmonary gangrene (Figure 2). Thoracic surgery was consulted the day after his arrival to LHSC. He was taken to the operating room and underwent a thoracotomy for debridement of necrotic lung in the right upper lobe (RUL) and RLL. The largest area of necrotic tissue measured $6 \mathrm{~cm} \times 10 \mathrm{~cm}$ and contained debris within the internal cavity, which was irrigated, in addition to multiple other smaller abscesses that were unroofed and debrided. Surgical pathology revealed necrotic lung tissue with abscess formation. Postoperatively, the patient experienced ongoing respiratory failure requiring tracheostomy and renal failure. After a 48-day hospitalization, he was discharged home.

\section{Case 5}

A 36-year-old woman presented to the emergency department of her local hospital with a 10-day history of weakness and cough. She was diagnosed with pneumonia and discharged home with a prescription for azithromycin as outpatient treatment. Four days later, she presented again to the community hospital in respiratory distress. On examination, she had visible cyanosis and was hypotensive, with lactic acidosis and a $\mathrm{pH}$ of 6.8. She was intubated, placed on vasopressors and empirical moxifloxacin. One blood culture, drawn at time of hospital admission, grew penicillin-sensitive $S$ pneumoniae. Serial CXRs showed worsening of the airspace disease, and she was unable to be weaned off ventilation. CT thorax demonstrated dense consolidation in both lungs, and a cavity in the RLL concerning for abscess formation. She was transferred to LHSC for further ICU management and consultation with a thoracic surgeon. At LHSC, the patient was treated with piperacillin/tazobactam. A repeat noncontrast CT scan showed bilateral diffuse consolidation and ground-glass opacities consistent with multifocal pneumonia, as well as a left-sided pneumothorax and large left pleural effusion. Within the densely consolidated LUL were multiple tiny round semisolid areas, each $<1 \mathrm{~cm}$ in diameter, which were concerning for cavity formation/developing microabscesses, and a $3 \mathrm{~cm} \times 2 \mathrm{~cm}$ cavity containing an air-fluid level within the RLL. A chest tube was inserted for the left-sided pneumothorax. The intensivist and thoracic surgeon continued medical management with antibiotics for cavitating pneumonia. She underwent a tracheostomy and, after 22 days, of mechanical ventilation, was weaned off ventilation. She was transferred back to her community hospital for further convalescence.

\section{DISCUSSION}

The mortality associated with CAP requiring ICU admission has recently been reported to be $30 \%$ (10) and historically as high as $54 \%$
(2). When CAP progresses to the point at which lung tissue becomes necrotic, mortality can be even higher. There are no practice guidelines to direct the care of patients with necrotizing pneumonia, and determining if and when surgical intervention is needed is challenging. The five cases reported here illustrate key considerations for recognition and appropriate management of necrotizing pneumonia.

\section{CLINICAL PRESENTATION, RADIOGRAPHY AND PATHOPHYSIOLOGY OF NECROTIZING LUNG INFECTIONS}

Necrotizing lung infections constitute a spectrum of disease severity ranging from simple lung abscess to necrotizing pneumonia to pulmonary gangrene (1). In all three of these categories, onset of disease is usually marked by the development of typical signs and symptoms of pneumonia. However, the clinical course and radiographic progression following initial onset may be quite different.

In the case of simple lung abscess, patients generally experience an indolent course, with a productive cough and fevers that fail to resolve despite usual courses of outpatient antibiotics. The patient may present to hospital weeks after onset of initial symptoms with signs of systemic chronic illness such as night sweats, weight loss and anemia. Pathologically, pneumonitis in the affected lobe progresses to a region of local tissue necrosis within seven to 14 days, becoming walled-off as a single cavity with a fibrous capsule. Initial radiographic examination may reveal a cavity within a pulmonary infiltrate. Serial $\mathrm{x}$-rays may show a single cavity, often containing an air-fluid level, for several weeks after the surrounding airspace disease has cleared. The abscess should drain spontaneously via the closest bronchus and resolve radiographically within six weeks during outpatient administration of antibiotics with anaerobic and polymicrobial coverage. Provided there is no pleural involvement, there is no need for assisted drainage of the lung abscess and surgical resection is unnecessary in the vast majority of cases. In the rare case in which a patient fails a prolonged course of appropriate antibiotic therapy, percutaneous drainage of a solitary lung abscess may be considered as an alternative to lobectomy in patients who are medically unfit for surgery due to comorbidities (11-15).

Despite sharing a similar pathological process, necrotizing pneumonia and pulmonary gangrene generally differ from lung abscess in their clinical course and radiographic features. As exemplified in these five cases, patients with necrotizing pneumonia or pulmonary gangrene may present to hospital severely ill with sepsis (Table 1) and expereince a rapid clinical deterioration, requiring ventilator support and/or exhibiting signs of septic shock within $72 \mathrm{~h}$ of presentation 
(Table 2). Radiographically, patients with necrotizing pneumonia present with more extensive airspace disease than patients with a lung abscess, often involving multiple lobes. Early in the course of disease, CXRs may reveal bulging fissures due to the intense inflammatory exudation present. Multiple small cavities, $<1 \mathrm{~cm}$, may only be visible on CT scan of the thorax. Necrotizing pneumonia has been defined radiographically as patchy inflammation with lack of perfusion (lack of contrast uptake in the parenchyma) and microabscesses on CT scan (1) (Figure 2B). As the lung tissue undergoes liquefactive necrosis, the multiple small abscesses may coalesce to form larger cavities (Figure 2A). With further necrosis and cavitation, the destructive process may progress to frank lobar gangrene.

Pulmonary gangrene represents the most severe end of the continuum of parenchymal destruction occurring in necrotizing lung infections. Although pulmonary gangrene and necrotizing pneumonia coexist on this spectrum, several authors $(1-3,5,16)$ make a distinction between these two categories of disease based on the extent of necrosis and presence of large-vessel thrombosis, which is believed to play a prominent role in the pathogenesis of pulmonary gangrene. Radiological criteria have been proposed for diagnosing pulmonary gangrene $(4,5)$. If a CT scan with contrast demonstrates obliteration of the pulmonary arterial supply to the segment or lobe containing large cavities and necrotic parenchyma, the disease process may be categorized as pulmonary gangrene (1). Bronchial obstruction may also be identified $(1,2)$. However, the sensitivity of these radiological criteria has not been established; therefore, absence of these findings does not rule out the presence of lung gangrene. Reimel et al (1) suggest that gangrene may be defined radiographically as a lack of perfusion with central necrosis affecting $>50 \%$ of the involved lobe, whereas a cavitary lesion occupying $\leq 50 \%$ of the affected lobe could be classified as a lung abscess. Occasionally, there is a movable mass of devitalized tissue within the cavity, creating the so-called 'air crescent sign' (5). Pathologically, organisms can be seen microscopically in the perivascular region of necrotizing pneumonia, whereas in pulmonary gangrene, the perivascular regions are devoid of microorganisms and extensive thrombosis of both large and small pulmonary arterial vessels is present. Bronchial arterial vessels may be obliterated, thrombosed or destroyed (5). The cavities that form in lung gangrene often lack the firm fibrous capsule found in a typical simple lung abscess (1). Despite these loosely distinguishing characteristics, it is important to remember that lung abscess, necrotizing pneumonia and pulmonary gangrene lay on a continuum, and may coexist in a single patient, as exemplified in the cases presented here.

The infecting microbes may influence whether a patient develops a simple lung abscess, necrotizing pneumonia or frank pulmonary gangrene. In lung abscesses, anaerobic bacteria from the gingival crevices are usually the causative factor, whereas in necrotizing pneumonia and pulmonary gangrene, anaerobes may be present although not believed to be the primary inciting organism (5). As exemplified in these cases, necrotizing pneumonia is most commonly caused by $S$ pneumoniae and $S$ aureus, which may be methicillin sensitive or methicillin resistant, and less commonly by Klebsiella and Haemophilus species, and Pseudomonas aeruginosa $(1,3)$. Of special concern is the emergence of a community-acquired MRSA strain containing the gene for PantonValentine leukocidin, a toxin known to cause necrotizing pneumonia with rapid progression to respiratory failure and shock and associated with a high mortality rate (17). Pulmonary gangrene is more often associated with Gram-negative organisms, particularly K pneumoniae and $P$ aeruginosa, but may also occur with $S$ pneumoniae $(1,5)$. It is not fully known why the same species of organism may cause a necrotizing lung infection in one host and a non-necrotizing pneumonia in another. Factors implicated include: overall health and immune status of the host; host inflammatory response; development of localized vasculitis with thrombosis of small and large vessels $(1,5)$; size of inoculum (5); and virulence and antibiotic resistance pattern of a particular strain of pathogen (17). Delays in seeking medical treatment or receiving appropriate antibiotics may also influence the propensity for developing a necrotizing lung infection, as described in cases 2 and 5 and other case reports in the literature (4).

\section{MANAGEMENT RECOMMENDATIONS}

As for any patient hospitalized with severe CAP and, particularly those who are critically ill, the focus of initial management is on early initiation of appropriate empirical antibiotics and attempting to identify the pathogen. Broad-spectrum antibiotics should be started immediately as per evidence-based guidelines $(18,19)$. Case 3 was started on penicillin and azithromycin on admission to the community hospital, but was found two days later to have K pneumoniae, not susceptible to the initial antibiotics prescribed. Local antibiotic susceptibility patterns should also inform the initial choice of antibiotics (eg, in regions with high rates of drug-resistant $S$ pneumonia or when risk factors for communityacquired MRSA are present) (18). Efforts should be made to identify the pathogen by obtaining sputum and blood cultures on hospital admission, in addition to urinary antigen tests for Legionella pneumophila and S pneumoniae $(18,19)$. For patients who cannot produce sputum, are immunocompromised or have risk factors for unusual organisms, fibreoptic bronchoscopy should be used to obtain a BAL or protected brush specimens of the affected lung region. For intubated patients, tracheobronchial aspiration, mini-BAL or BAL should be used to identify a pathogen $(18,19)$. Up to $40 \%$ of patients with CAP admitted to the ICU will experience clinical deterioration after initial stabilization. Therefore, early identification of the pathogen and its antibiotic sensitivities is important to ensuring appropriate antibiotic coverage $(18,19)$.

S pneumoniae is identified as the pathogen in CAP in $30 \%$ to $60 \%$ of cases (6), and is a common pathogen in both the pediatric and adult population for necrotizing pneumonia (7). Several risk factors for pneumococcal pneumonia have previously been identified: smoking, underlying lung disease, diabetes mellitus and alcohol misuse $(2,4,10,20,21)$. All but one of our patients had at least one of these risk factors (Table 1). As a means of preventing the potentially serious sequelae of pneumococcal pneumonia, pneumococcal vaccination should be offered to adults with any risk factors for invasive pneumococcal disease, including positive smoking status, regardless of age (12).

After initiation of antibiotic treatment and investigations to identify the pathogen, the focus should be placed on monitoring the patient for adequacy of source control. Inadequate source control with antibiotics alone may emanate from two broad categories of pulmonary complications: pleural involvement and/or a progressive parenchymal necrotizing infection. Serial CXRs or thoracic ultrasound examinations are useful for identifying the development of pleural effusions. Parapneumonic pleural fluid should be sampled and drained if pus or bacteria are present, it is loculated or the $\mathrm{pH}<7.2(18,19)$. A CT scan with contrast is also useful to look for pleural thickening and enhancement suggestive of empyema and to evaluate multiseptated or loculated effusions not responding to chest tube drainage that may require insertion of additional chest tubes, fibrinolytic therapy or surgical intervention to achieve adequate drainage and source control.

To evaluate for the presence of a necrotizing pneumonia, serial radiographic evaluation is essential. Daily CXRs may reveal rapid progression of airspace disease and the development of a cavity, although necrosis may be advanced by the time it is apparent on plain film. Figure 1 demonstrates how the CXR may significantly underestimate the extent of cavitation. CT thorax is the most sensitive diagnostic test for necrotizing pneumonia. CT thorax is indicated for hospitalized patients with progressive pneumonia, defined as acute deterioration with respiratory failure and/or septic shock within $72 \mathrm{~h}$, or nonresponding pneumonia, defined as the persistence of fever $>38^{\circ} \mathrm{C}$ and/or clinical symptoms after at least $72 \mathrm{~h}$ of antibiotic treatment $(18,22)$, or when cavitation is suspected on plain film. The pattern of clinical decline may help differentiate patients with necrotizing pneumonia from patients with sepsis related to nonresponding - but non-necrotizing - pneumonia. Necrotizing pneumonia is more likely to present as a 'progressive pneumonia', whereas in the latter, clinical deterioration or signs of persistent infection occurring after $72 \mathrm{~h}$ of 
antibiotic therapy is often due to an intercurrent complication such as superimposed nosocomial pneumonia, persistence of the initial bacterial pathogen due to antibiotic resistance or noncoverage of atypical community-acquired bacteria $(18,22)$. However, CT of the thorax is necessary to rule out a necrotizing infection in patients with both rapid and slow clinical deteriorations.

CT of the thorax revealing the presence of multiple small abscesses, indicative of early cavitation and necrotizing pneumonia, should prompt consultation with a thoracic surgeon and follow-up CT imaging to examine for risk factors for inadequate source control despite adequate medical therapy. The presence of lung abscesses distal to a bronchus that is narrowed by inflammation or obliterated completely will make spontaneous drainage difficult and may prompt surgical intervention. Ideally, a CT thorax with contrast is recommended to evaluate the blood supply to the lung parenchyma (Figure 2) because medical therapy is more likely to fail in the presence of significant vascular obstruction. Although the risk for contrast-induced nephropathy $(\mathrm{CIN})$ is a common concern in critically ill patients, a recent prospective, matched cohort study of ICU patients showed that overall, the incidence of CIN was relatively low in this population and that ICU patients undergoing noncontrast CT scans were as likely to experience a decline in creatinine clearance postscan as those receiving contrast for CT scans (23). Therefore, clinicians must weigh the diagnostic benefit of a contrast-enhanced CT scan against the possibly low incremental risk of CIN.

Although it is not always possible to distinguish necrotizing pneumonia from pulmonary gangrene radiographically, establishing a diagnosis of pulmonary gangrene will facilitate the decision to proceed with surgery. Obliteration of the pulmonary arterial supply to the segment or lobe containing necrotic parenchyma (5), or lack of contrast uptake in the lung parenchyma with central necrosis affecting $>50 \%$ of the involved lobe (1), is indicative of pulmonary gangrene. The accepted treatment for pulmonary gangrene is appropriate antimicrobial therapy and surgical debridement of the sloughed lung parenchyma.

The discovery of concomitant underlying structural lung disease and the patient's previous comorbidities will factor into the suitability of the patient for surgical pulmonary resection. Percutaneous drainage of lung abscess cavities is described in the literature as an alternative to lobectomy for treatment of a solitary lung abscess that has failed medical management (11-15). However, percutaneous drainage is not recommended for necrotizing pneumonia $(8,9,15)$ for several reasons. First, a percutaneously inserted catheter may drain an associated collection but does not debride the necrosing parenchymal tissue responsible for the systemic inflammatory response in the critically ill patient and is unlikely to control sepsis. Furthermore, in the setting of necrotizing pneumonia, catheters placed in the lung parenchyma become easily obstructed with sloughed necrotic debris and are not amenable to thrombolytic therapy due to the risk of hemoptysis. Finally, in addition to the lack of demonstrated benefit, there is increased risk for harm. Percutaneous drains for necrotizing pneumonia are associated with a high incidence of bronchopleural fistulas and persistent pneumothoraces (15), which may be due to the lack of a firm fibrous capsule surrounding the cavitation that typically forms around a simple lung abscess. Therefore, in cases of necrotizing pneumonia that are failing medical management, or multilobar pulmonary gangrene, open surgical debridement of devitalized tissue is necessary.

\section{SURGICAL OPTIONS}

Operative interventions for acute lung infections fall into two broad categories: management of pleural disease, including empyema and bronchopleural fistula; and management of progressive parenchymal necrotizing infection. Accepted indications for surgical resection of lung parenchyma in the setting of acute necrotizing lung infections include massive hemoptysis and pulmonary gangrene $(3-5,16,24)$. A necrotizing pneumonia not responding to supportive treatment is an additional potential indication for surgery (3). Surgical resection for acute necrotizing pneumonia has been described in the literature, $(1-4,6)$; however, the indications and optimal timing for surgery are unclear. Such patients are often at high risk for surgery due to hemodynamic instability and impaired oxygenation. Furthermore, such patients usually have concomitant acute lung injury and systemic inflammatory response syndrome, which may be accelerated during surgery. If pulmonary blood supply is largely maintained, antibiotic treatment and supportive therapy does have the potential to be effective. Reimel et al (1) reported on 17 patients with necrotizing pneumonia in whom CT with contrast showed that the majority of lung parenchyma was perfused; these patients had resolving sepsis, did not require surgery and were followed with interval CT scans until discharge. However, patients with necrotizing pneumonia are also at risk for bacterial contamination of the contralateral lung, progressive septic shock, multiorgan failure and death if the necrotizing infection does not respond to supportive antibiotic therapy. The risk associated with surgical resection versus the risk of developing complications of necrotizing pneumonia are not well defined (3). Three retrospective cohort studies of patients undergoing surgical lung resection for necrotizing pneumonia and pulmonary gangrene report mortality rates of $9 \%, 15 \%$ and $20 \%(1,9,24)$; however, these data are limited by sample size and lack of a comparator group of patients not undergoing surgery. Eleven percent to $13 \%$ of these patients remained ventilator dependent postoperatively $(1,24)$. No other data are reported in the literature regarding long-term morbidity.

Optimal timing of surgery is uncertain. The largest reported case series of surgical management of necrotizing pneumonia (Reimel et al [1]) suggest that waiting until patients have been medically stabilized allows for better surgical outcomes. The authors reason that delaying surgery provides time for "areas of lung that had documented perfusion... to resolve, further localizing the area that actually required resection" (1). The risk of delaying surgical intervention, however, is that the patient's condition may worsen in the interim. In our case series, one of the three patients who underwent surgery died: this patient (case 1), went to the operating room 11 days after initial presentation, with a higher Sepsis-related Organ Failure Assessment score on the day of surgery than the day of admission to hospital, indicating a deteriorating course at the time of surgery (Table 2). The other patient who died (case 3) was deemed too unstable for the operating room when thoracic surgery was consulted 18 days after her initial presentation. These cases raise the question of whether there may have been an earlier time window during which surgical intervention may have resulted in better outcomes. A second risk of delaying surgery is that a patient with unilateral pneumonia may progress to experience bilateral involvement with pneumonia or inflammation/ lung injury. Reimel et al (1) reported on eight intubated patients with diffuse bilateral airspace disease who underwent surgery for necrotizing pneumonia, three of whom died and two remained chronically ventilator dependent.

Presurgical interventions should include chest tube placement to drain complicated pleural effusions or empyema, and correction of any coagulopathy $(1,24)$. When an operation is deemed necessary, the goals of surgery are to control the ongoing sepsis, drain the empyema, unroof lung abscesses, resect or debride necrotic tissue, re-expand the lung and protect the contralateral lung from spillage while trying to avoid large spatial voids and large bronchopleural fistulas (1). We do not recommend video-assisted thoracoscopic surgery because these patients often cannot tolerate single lung ventilation $(1,3)$. Furthermore, it is easier to distinguish viable from nonviable tissue with an open thoracotomy approach, thereby optimizing the debridement or resection. Options for resection include wedge resection, segmentectomy, lobectomy or pneumonectomy $(1,3)$. A fenestration (window) may be considered if the patient's condition prohibits a resection (25).

At our centre, patients return to the ICU after surgery, with up to four chest tubes in situ to drain potential spaces (anterior, lateral, posterior and diaphragm) and air leak from the denuded lung. In our 
experience, air leaks usually heal spontaneously; however, if the patient is left with a bronchopleural fistula and space problem, it can be dealt with surgically at a later time. It is important for clinicians to be aware that patients may worsen after surgery before they get better. The systemic inflammatory response syndrome response may also be augmented by surgery; therefore, clinicians must be prepared for the possibility of unstable hemodynamics intra- and postoperatively. Furthermore, the lung will be contused postoperatively with further inflammation and capillary leak; hence, protective lung ventilation strategies are appropriate. We advocate that antibiotics be continued postoperatively, along with a special focus on nutrition, physiotherapy and rehabilitation. In cases for which surgical debridement or resection was necessary for controlling the source of sepsis, recovery, albeit slow, is possible.

\section{SUMMARY}

CAP requiring ICU admission is associated with high morbidity and mortality, particularly when necrotizing pneumonia develops. Early broad-spectrum antibiotics, bronchoscopy to identify pathogens and chest tubes to drain empyemas are important early interventions to optimize medical management. CT thorax is indicated for patients with progressive pneumonia or nonresponding pneumonia, and may show evidence of necrotizing pneumonia. If necrotizing pneumonia is

\section{REFERENCES}

1. Reimel BA, Krishnadasen B, Cuschieri J, Klein MB, Gross J, Karmy-Jones R. Surgical management of acute necrotizing lung infections. Can Respir J 2006;13:369-73.

2. Penner C, Maycher B, Long R. Pulmonary gangrene.

A complication of bacterial pneumonia. Chest 1994;105:567-73.

3. Krishnadasan B, Sherbin VL, Vallieres E, Karmy-Jones R.

Surgical management of lung gangrene. Can Respir J 2000;7:401-4.

4. Hammond JM, Lyddell C, Potgieter PD, Odell J.

Severe pneumococcal pneumonia complicated by massive pulmonary gangrene. Chest 1993;104:1610-2.

5. Curry CA, Fish aEK, Buckley JA. Pulmonary gangrene:

Radiological and pathologic correlation. South Med J 1998;91:957-60.

6. Chen C-H, Huang W-C, Chen T-Y, Hung T-T, Liu H-C, Chen C-H. Massive necrotizing pneumonia with pulmonary gangrene. Ann Thor Surg 2009;87:311.

7. Hsieh YC, Hsiao CH, Tsao PN, et al. Nectorizing pneumococcal pneumonia in children: The role of pulmonary gangrene. Pediatr Pulmonol 2006;41:623-9.

8. Alifano M, Lorut C, Lefebvre A, et al. Necrotizing pneumonia in adults: Multidisciplinary management. Intensive Care Med 2011;37:1888-9.

9. Schweigert M, Dubecz A, Beron M, Ofner D, Stein HJ. Surgical therapy for necrotizing pneumonia and lung gangrene. Thorac Cardiovasc Surg 2013;61:636-41.

10. Laterre P-F. Severe community acquired pneumonia update: Mortality, mechanisms and medical intervention. Crit Care 2008;12(Supp 6):S1.

11. Shim C, Santos GH, Zelefsky M. Percutaneous drainage of lung abscess. Lung 1990;168:201-7.

12. Vainrub B, Musher DM, Guinn GA, Young EJ, Septimus EJ, Travis LL. Percutaneous drainage of lung abscess. Am Rev Respir Dis 1978;117:153-60.

13. Kosloske AM, Ball WS Jr, Butler C, Musemeche CA. Drainage of pediatric lung abscess by cough, catheter, or complete resection. J Pediatr Surg 1986;21:596-600.

14. Pages PB, Bernard A. [Lung abscess and necrotizing pneumonia: Chest tube insertion or surgery?] Rev Pneumol Clin 2012;68:84-90. suspected on initial CT thorax, a follow-up CT thorax with contrast is recommended to assess for evidence of pulmonary gangrene. The presence of pulmonary gangrene is widely accepted as an indication for surgery. However, in the absence of pulmonary gangrene, it is unknown whether surgical resection for necrotizing pneumonia is superior to medical management. Repeat CT scans should be considered promptly when a change in the patient's status occurs or when recovery is not occurring as expected. Our practice has evolved to encourage earlier surgical intervention if there is no improvement in the patient's condition despite optimal antibiotics. Consultation with a thoracic surgeon early in the course of managing a patient with necrotizing pneumonia is appropriate. However, further research is required to elucidate the indications and optimal timing of surgical intervention for necrotizing pneumonia and the relative risks and benefits.

ACKNOWLEDGEMENTS: NC wrote the initial draft of the manuscript, DF and KB revised the manuscript. The authors thank Ms Jeanette Mikulic, Ms Linda Wunnink, Mr Dave Rutherford and Dr David Leasa for their assistance with preparation and review of the manuscript.

DISCLOSURES: The authors have no financial disclosures or conflicts of interest to declare.

15. Hoffer FA, Bloom DA, Colin AA, Fishman SJ. Lung abscess versus necrotizing pneumonia: Implications for interventional therapy. Pediatr Radiol 1999;29:87-91.

16. Knight L, Fraser RG, Robson HG. Massive pulmonary gangrene: A severe complication of Klebsiella pneumonia. Can Med Assoc J 1975;112:196-8.

17. Gillet Y, Vanhems P, Lina G, et al. Factors predicting mortality in necrotizing community-acquired pneumonia caused by Staphylococcus aureus containing Panton-Valentine leukocidin. Clin Infect Dis 2007;45:315-21.

18. Mandell LA, Wunderink RG, Anzueto A, et al. Infectious Diseases Society of America/American Thoracic Society consensus guidelines on the management of community-acquired pneumonia in adults. Clin Infect Dis 2007;44(Suppl 2):S27-S72.

19. Mandell LA, Marrie TJ, Grossman RF, Chow AW, Hyland RH. Canadian guidelines for the initial management of communityacquired pneumonia: An evidence-based update by the Canadian Infectious Diseases Society and the Canadian Thoracic Society. The Canadian Community-Acquired Pneumonia Working Group. Clin Infect Dis 2000;31:383-421.

20. de Roux A, Cavalcanti M, Marcos MA, et al. Impact of alcohol abuse in the etiology and severity of community-acquired pneumonia. Chest 2006;129:1219-25.

21. Talbot TR, Hartert TV, Mitchel E, et al. Asthma as a risk factor for invasive pneumococcal disease. N Engl J Med 2005;352:2082-90.

22. Arancibia F, Ewig S, Martinez JA, et al. Antimicrobial treatment failures in patients with community-acquired pneumonia: Causes and prognostic implications. Am J Respir Crit Care Med 2000;162:154-60.

23. Cely CM, Schein RM, Quartin AA. Risk of contrast induced nephropathy in the critically ill: A prospective, case matched study. Crit Care 2012;16:R67.

24. Karmy-Jones R, Vallieres E, Harrington R. Surgical management of necrotizing pneumonia. Clin Pulm Med 2003;10:17-25.

25. Refaely Y, Weissberg D. Gangrene of the lung: Treatment in two stages. Ann Thorac Surg 1997;64:970-3. 


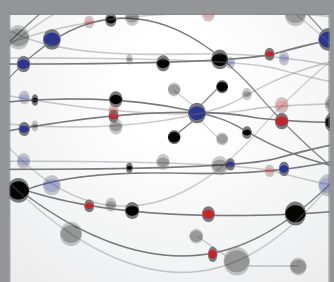

The Scientific World Journal
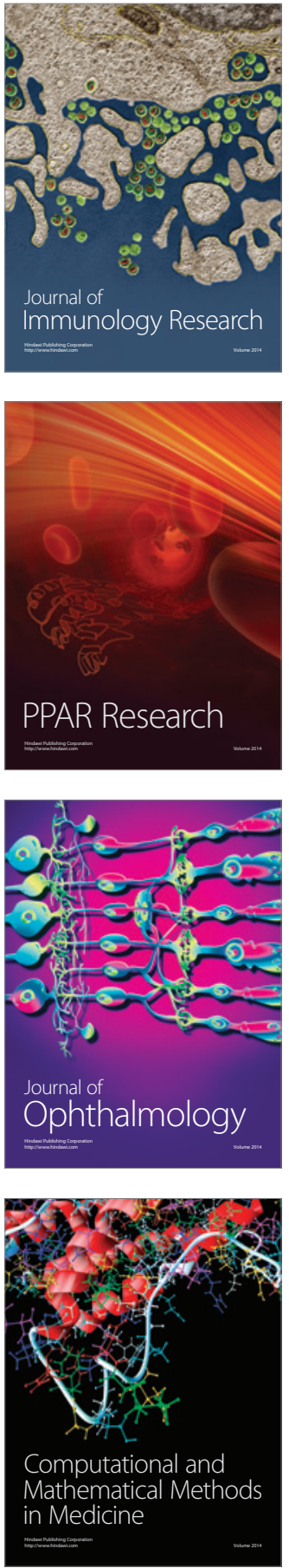

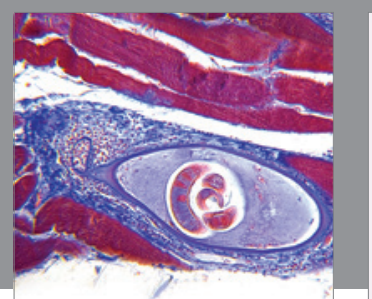

Gastroenterology Research and Practice

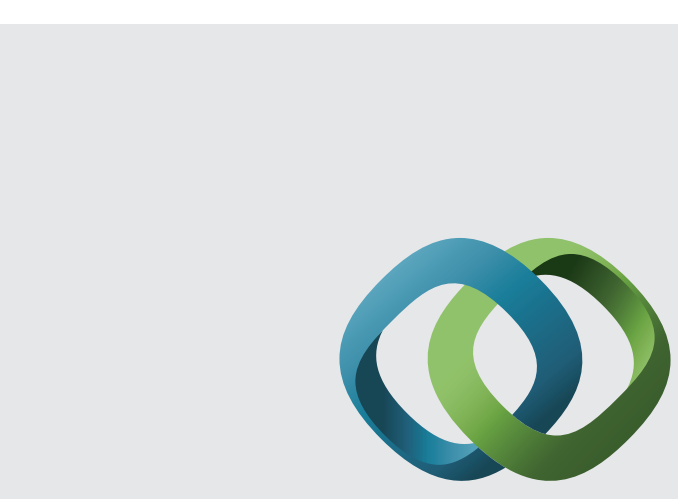

\section{Hindawi}

Submit your manuscripts at

http://www.hindawi.com
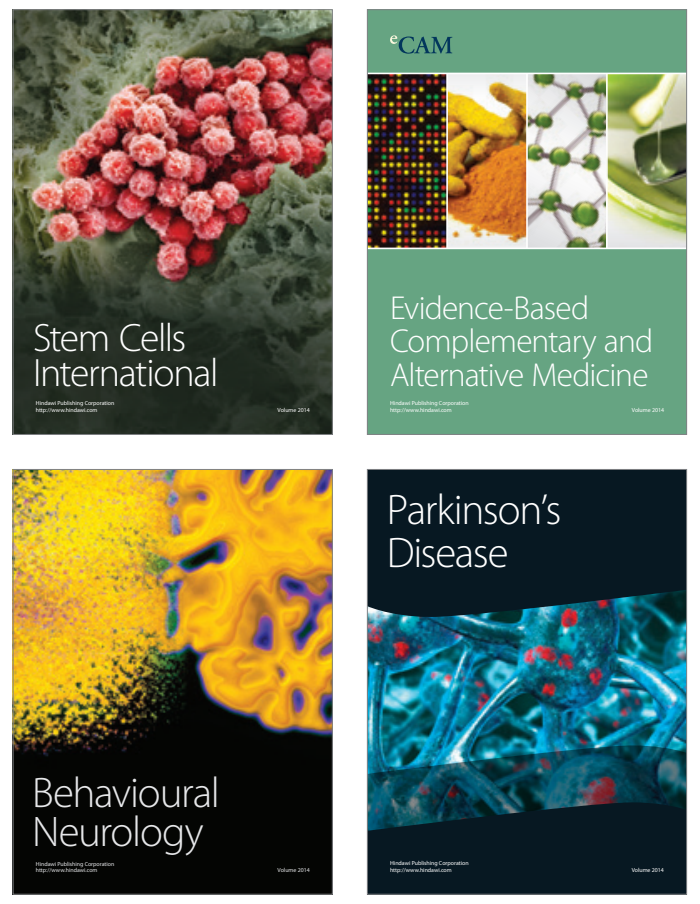
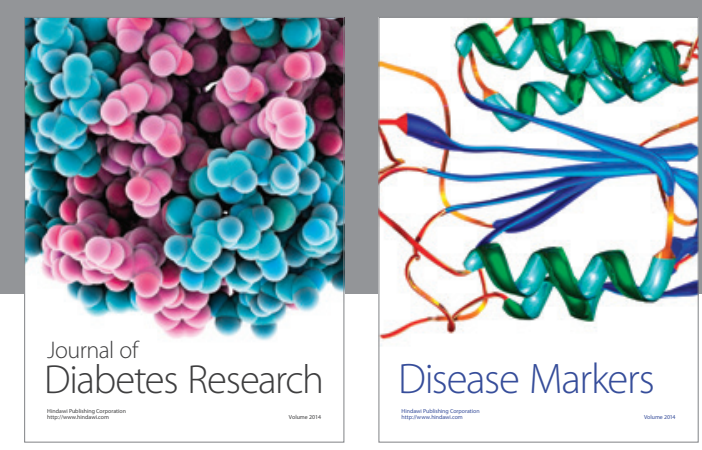

Disease Markers
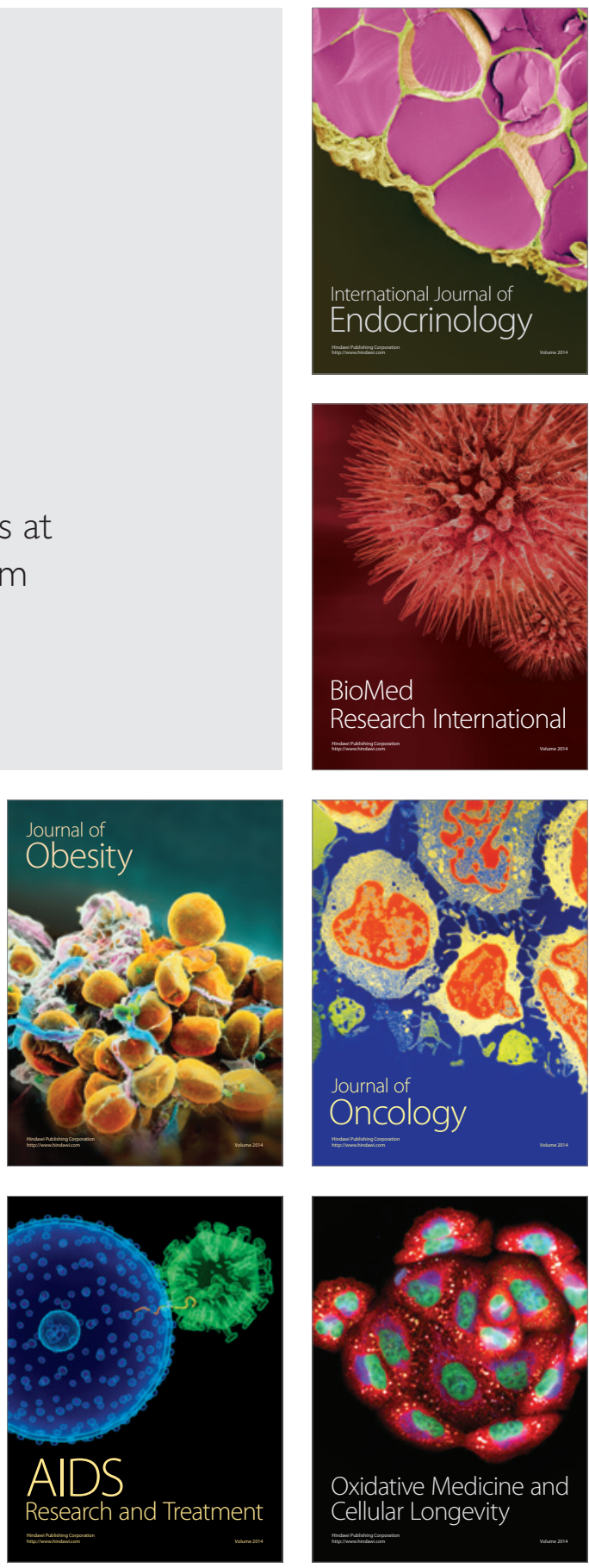